\title{
Tratamentos pré-germinativos em sementes de granadilha (Passiflora ligularis)
}

\author{
Pre-germination treatment in granadilha (Passiflora ligularis) seeds
}

\section{Danielle Acco Cadorin, Fabíola Villa*, Graciela Maiara Dalastra, Karina Heberle e Maria Cristina Copello Rotili}

\author{
Recebido em 18/04/2016 / Aceito em 14/03/2017
}

\section{RESUMO}

A granadilha é um maracujá doce, sendo os frutos consumidos in natura. O principal método de propagação de mudas é via sexuada, porém com baixa taxa de germinação devido a dormência encontrada nas sementes. Diante do exposto, objetivou-se com o presente trabalho avaliar o ácido giberélico e temperatura na germinação de sementes de granadilha. $\mathrm{O}$ delineamento experimental utilizado foi inteiramente casualizado, em esquema fatorial 2 (temperaturas, sendo $25^{\circ} \mathrm{C}$ constante, e 20-30 ${ }^{\circ} \mathrm{C}$ alternados) $\times 2$ (100 $\mathrm{mg} \mathrm{L}^{-1}$ de ácido giberélico e ausência), contendo quatro repetições e 50 sementes por repetição. Avaliaram-se a cada dois dias, até 60 dias a percentagem de germinação, índice de velocidade de germinação, tempo médio de germinação, altura $(\mathrm{mm})$ e biomassa seca $(\mathrm{mg})$ de plântulas. Melhores resultados foram obtidos para as sementes de granadilha foram verificados com a utilização de $100 \mathrm{mg} \mathrm{L}^{-1}$ de $\mathrm{GA}_{3}$ e em temperatura alternada de 20-30 ${ }^{\circ} \mathrm{C}$. Maior percentagem de germinação de sementes de granadilha foi $53,2 \%$ na temperatura de $20-30{ }^{\circ} \mathrm{C}$ alternado.

PALAVRAS-CHAVE: maracujá doce, teste de germinação, propagação sexuada, fitormônio.

\section{ABSTRACT}

The granadilha is a sweet passion fruit, and the fruit is consumed while fresh. The method for seedling propagation is via sexual, but germination rates are low due to dormancy found in the seeds. The aim of the present study was to evaluate gibberellic acid and temperature in granadilha seed germination. The experimental design was completely randomized in a factorial 2 (temperature, $25{ }^{\circ} \mathrm{C}$ constant, and alternating $\left.20-30{ }^{\circ} \mathrm{C}\right) \times 2\left(100 \mathrm{mg} \mathrm{L}^{-1}\right.$ of gibberellic acid and absence), containing 5 replications and 80 seeds per repetition. They were evaluated every two days, until sixty days' germination percentage, for germination speed index, germination velocity time, height $(\mathrm{mm})$ and dry weight $(\mathrm{mg})$ of seedlings. Best results were obtained for the granadilha seeds were found using $100 \mathrm{mg} \mathrm{L}^{-1}$ of $\mathrm{GA}_{3}$ and alternating temperatures of $20-30{ }^{\circ} \mathrm{C}$. The highest percentage of granadilha seed germination was $53.2 \%$ at the temperature of $20-30{ }^{\circ} \mathrm{C}$ alternating.

KEYWORDS: sweet passion fruit, germination test, sexual propagation, plant growth regulator.

\section{INTRODUÇÃO}

O maracujazeiro é originário da América Tropical, com mais de 150 espécies dentro da família Passifloraceae, utilizadas para consumo humano (SABIÃO et al. 2011). No Brasil as espécies de maracujazeiro mais cultivadas são o azedo ou amarelo (Passiflora edulis f. flavicarpa), roxo (Passiflora edulis) e doce (Passiflora alata) (LIMA et al. 2009).

A espécie Passiflora ligularis, conhecida como granadilha, é um maracujá doce, sendo seus frutos consumidos in natura. Devido às características nutricionais, os frutos têm um elevado potencial de exportação (RODRÍGUEZ \& BERMÚDEZ 2009), mas a cultura tem baixa produtividade, pois $\mathrm{o}$ método de propagação mais utilizado é via semente, obtendo assim uma baixa (em torno de $20 \%$ ), lenta e desuniforme taxa de germinação, o que dificulta a formação das mudas (POSADA et al. 2014, SOUZA et al. 2015).

Essa baixa e lenta germinação é decorrente da dormência que as sementes do gênero Passiflora apresentam, necessitando assim de tratamentos 
para sua superação (OLIVEIRA JR. et al. 2010). Existem diversos tratamentos aos quais as sementes de Passiflora podem ser submetidas para a quebra dessa dormência, dentre eles o uso de fitormônios, principalmente a base de giberelinas e também a temperatura a qual as sementes são expostas (REGO et al. 2014).

Fitormônios como giberelinas, citocininas e etileno são promotores da germinação. As giberelinas têm ação na síntese de proteínas e RNA específicos na germinação, tanto na quebra da dormência como no controle da hidrólise de reservas, da qual depende o embrião em crescimento (TAIZ \& ZEIGER 2013). Além do estudo dos efeitos dos reguladores vegetais na germinação de sementes, cabe salientar a necessidade do conhecimento das fases da germinação, inclusive para a determinação de tempos de embebição com os reguladores, conforme reportado por FERRARI et al. (2008) e SANTOS et al. (2015), em estudo com algumas espécies do gênero Passiflora.

Além dos fitormônios, a temperatura influencia na velocidade e na uniformidade de germinação, na velocidade de absorção de água e, portanto, nas reações bioquímicas que determinam todo o processo. Assim, a germinação só ocorre dentro de determinados limites de temperatura, os quais englobam uma temperatura, ou faixa de temperatura, onde o processo ocorre com máxima eficiência (CARVALHO \& NAKAGAWA 2012).

Apesar das inúmeras pesquisas com germinação de espécies frutíferas do gênero Passiflora, pouco se fala sobre a $P$. ligularis e problemas ocorridos durante o processo de germinação e posteriores, como viabilidade e período de armazenamento, importantes para melhoria da produção de mudas frutíferas de qualidade. Diante do exposto, objetivouse com o presente trabalho avaliar tratamentos prégerminativos de sementes de granadilha, por meio de temperatura e ácido giberélico, a fim de dar suporte a futuros estudos sobre emergência e desenvolvimento de mudas.

\section{MATERIAL E MÉTODOS}

O experimento foi realizado no Laboratório de Sementes e Mudas da Universidade Estadual do Oeste do Paraná, Campus Marechal Cândido Rondon, PR, no período de junho a setembro de 2015. Frutos de granadilha foram adquiridos de fruticultor idôneo do município de Marechal Cândido Rondon, PR, sendo estes selecionados em função das seguintes características: maduros, tamanho uniforme, inteiros, limpos, de consistência firme, isentos de ataques de insetos e outros defeitos físicos aparentes. Os frutos foram seccionados no sentido do seu comprimento, sendo suas sementes retiradas em condições de Laboratório.

As sementes extraídas, juntamente com a mucilagem, foram acondicionadas em balde plástico por três dias, ocorrendo neste período fermentação, sendo na sequência lavadas em água corrente para a eliminação da mucilagem e secas à sombra sobre papel jornal, por dois dias, em temperatura ambiente. Após a secagem, as sementes foram armazenadas em saco plástico transparente, dentro de um vidro transparente, hermeticamente fechado e mantido em geladeira à temperatura de $13{ }^{\circ} \mathrm{C}$ até sua utilização. Após três dias, as sementes foram dispostas nos seus devidos tratamentos.

Antes da instalação do experimento, verificouse o teor de água das sementes, determinado pelo método de estufa a $105 \pm 3{ }^{\circ} \mathrm{C}$ por 24 horas (BRASIL 2009), com os resultados expressos em percentagem. Em seguida, as sementes foram submetidas aos testes de germinação.

O delineamento experimental utilizado foi inteiramente casualizado, em esquema fatorial $2 \times 2$ (2 temperaturas de germinação $\mathrm{x}$ ácido giberélico), contendo cinco repetições e 80 sementes por repetição. $\mathrm{O}$ primeiro fator correspondeu a duas temperaturas durante a germinação $\left(25^{\circ} \mathrm{C}\right.$ constante, e $20-30{ }^{\circ} \mathrm{C}$ alternados por 8 e 16 horas) e o segundo fator a presença ou ausência de tratamento com ácido giberélico $\left(\mathrm{GA}_{3}\right)$.

O tratamento com ácido giberélico foi realizado com aplicação de fitormônio sob forma de $\mathrm{GA}_{3}$, na concentração de $100 \mathrm{mg} \mathrm{L}^{-1}$ mediante imersão das sementes em solução preparada com o fitorregulador por um período de 15 minutos. O mesmo ocorreu para as sementes embebidas apenas em água destilada, por 15 minutos.

Para o teste de germinação foram utilizadas cinco repetições de 80 sementes, distribuídas uniformemente sobre papel germistest e acondicionadas em caixas tipo gerbox. O papel foi umedecido com água destilada na proporção de 2,5 vezes o seu peso seco. Durante o período de germinação, as caixas foram mantidas em câmara de germinação regulada com as temperaturas que consistiram nos tratamentos e fotoperíodo de 8/16 horas de luz e escuro, respectivamente. A umidade 
do substrato foi monitorada, periodicamente, adicionando-se água sempre que necessário.

As contagens do teste de germinação foram realizadas a cada dois dias por 60 dias, momento em que a germinação não foi mais verificada, sendo computada a percentagem de plântulas normais. Com base na contagem da germinação foram calculados o índice de velocidade de germinação (MAGUIRE 1962) e tempo médio de germinação (LABOURIAU 1983).

O comprimento das plântulas normais foi mensurado com régua graduada, sendo os resultados expressos em milímetros e a biomassa seca das plântulas foi obtida através da secagem em estufa com circulação de ar forçada a $65^{\circ} \mathrm{C}$ até peso constante, sendo os resultados expressos em mg/plântula. As duas avaliações foram feitas 60 dias após a germinação.

Os dados observados foram submetidos a normalidade de distribuição dos resíduos, pelo teste de Shapiro-Wilk e, posteriormente, submetidos à análise da variância com auxílio do programa estatístico Sisvar (FERREIRA 2011). Quando da existência de diferenças estatisticamente significativas, as médias foram comparadas pelo teste de Tukey, a 5\% de probabilidade de erro.

\section{RESULTADOS E DISCUSSÃO}

A interação entre temperatura e ácido giberélico não exerceu influência sobre as variáveis analisadas. Porém, o efeito isolado da temperatura e ácido giberélico influenciou todas as variáveis estudadas na germinação das sementes de granadilha.

Em relação as sementes submetidas as temperaturas, pode-se verificar na Tabela 1, que em 20$30{ }^{\circ} \mathrm{C}$ alternados, maior percentagem de germinação, índice de velocidade de germinação, comprimento das plântulas, biomassa seca de plântulas e menor tempo médio de germinação.

O comprimento da parte aérea das plântulas foi influenciado positivamente com temperaturas alternadas. Certamente esse resultado pode ser explicado, uma vez que a temperatura alternada é favorável ao processo germinativo e quebra de dormência, com resposta positiva para o comprimento da parte aérea. Sementes mais vigorosas, com melhor desempenho fisiológico, originarão plântulas com maiores taxas de desenvolvimento, em função destas apresentarem maior capacidade de transformação dos tecidos (AMARO et al. 2014).

Ainda na Tabela 1, verifica-se melhores resultados para a biomassa seca de plântulas, percentagem de germinação e índice de velocidade de germinação foram observados com a utilização de temperaturas alternadas. Muitas espécies apresentam resposta germinativa favorável quando são submetidas a temperaturas alternadas, situação que se assemelha às condições encontradas em ambientes naturais, em que as temperaturas durante o dia são maiores que as noturnas (CARVALHO \& NAKAGAWA 2012).

Para a maioria das espécies tropicais e algumas espécies de Passiflora, a temperatura ótima de germinação encontra-se entre a faixa de 15 a $30{ }^{\circ} \mathrm{C}$ (ALVES et al. 2011), e o máximo poder germinativo

Tabela 1. Comprimento de plântulas (COMP), biomassa seca de plântulas (BMSP), percentagem de germinação (PG), índice de velocidade de germinação (IVG) e tempo médio de germinação (TMG) de sementes de granadilla, submetidas as temperaturas.

Table 1. Seedling length (COMP), dry weight of seedling (BMSP), germination percentage (PG), emergence velocity index (IVG) and mean germination time (TMG) of sweet granadilla passion fruit seeds under temperatures.

\begin{tabular}{lccccc}
\hline \multirow{2}{*}{ Temperaturas } & COMP & BMSP & PG & IVG & TMG \\
\cline { 2 - 6 } & $(\mathrm{cm})$ & $(\mathrm{mg} /$ plântula $)$ & $(\%)$ & & $($ dias $)$ \\
\hline $25^{\circ} \mathrm{C}$ & $2,02 \mathrm{~b}^{*}$ & $2,43 \mathrm{~b}$ & $23 \mathrm{~b}$ & $0,3968 \mathrm{~b}$ & $15,94 \mathrm{a}$ \\
$20-30^{\circ} \mathrm{C}$ & $3,19 \mathrm{a}$ & $6,71 \mathrm{a}$ & $53,2 \mathrm{a}$ & $0,8943 \mathrm{a}$ & $14,96 \mathrm{~b}$ \\
\hline $\mathrm{CV}(\%)$ & 7,75 & 14,87 & 11,62 & 23,30 & 4,86
\end{tabular}

*Médias seguidas de mesma letra minúscula na coluna não diferem estatisticamente entre si, pelo Teste de Tukey, a $5 \%$ de probabilidade de erro. 
pode ser obtido por alternância de temperatura (ZUCARELI et al. 2009). Este comportamento pode estar associado à dormência de sementes, embora a alternância de temperatura possa também acelerar a germinação de sementes não dormentes (WELTER et al. 2011).

A temperatura exerce grande influência sobre as reações bioquímicas que regulam o metabolismo necessário para iniciar o processo de germinação, e em consequência, sobre a porcentagem e a velocidade do processo, sendo o comportamento muito diferenciado entre espécies (CARVALHO \& NAKAGAWA 2012), principalmente entre espécies frutíferas do gênero Passiflora (ZUCARELI et al. 2015).

Resultados semelhantes aos encontrados no presente trabalho foram reportados por ZUCARELI et al. (2009), onde afirmaram que a temperatura alternada de $20-30{ }^{\circ} \mathrm{C}$ atuou significativamente na obtenção de maior percentagem de plântulas normais oriundas de sementes de $P$. cincinnata. Esses resultados parecem elucidar um comportamento comum para espécies frutíferas do gênero Passiflora.

Verifica-se na Tabela 2, influência positiva quando utilizado o ácido giberélico, sugerindo que sementes de granadilha possuem dormência fisiológica. MARCOS FILHO (2015) conceituou a dormência como a falta de capacidade temporária da semente germinar mesmo quando exposta a condições ambientais favoráveis. A dormência pode ser regulada por mecanismos de origem embrionária, tegumentar, química (inibidores) ou fisiológica (balanço hormonal). Adicionalmente, pode estar relacionada com a combinação desses mecanismos, que, por sua vez, são influenciados por fatores externos (MARCOS FILHO 2015).

$\mathrm{Na}$ Tabela 2 verifica-se menor tempo médio de germinação de sementes de granadilha com a utilização de ácido giberélico. As giberelinas são hormônios que estão envolvidos na modulação do desenvolvimento de todo o ciclo vegetal e destacamse por serem eficientes em promover a superação da dormência em sementes (TAIZ \& ZEIGER 2013). Estas agem também aumentando o potencial de crescimento do embrião e controlam o crescimento do eixo embrionário, induzem a síntese de hormônios relacionados com o crescimento das plântulas e enzimas que degradam amido no endosperma (CAVUSOGLU \& SULUSOGLU 2015).

CÁRDENAS et al. (2013) estudando concentrações de ácido giberélico, observaram redução no tempo médio de germinação com a embebição de sementes de granadilha em $100 \mathrm{mg} \mathrm{L}^{-1}$ de $\mathrm{GA}_{3}$, quando comparado a utilização de $400 \mathrm{mg} \mathrm{L}^{-1}$ de $\mathrm{GA}_{3}$. Os resultados obtidos corroboram PÁDUA et al. (2011) e FERRARI et al. (2008), os quais verificaram que a embebição de sementes de maracujá doce em soluções contendo 100,150 e $250 \mathrm{mg} \mathrm{L}^{-1}$ de $\mathrm{GA}_{3}$ alterou a percentagem total de germinação.

$\mathrm{O}$ efeito benéfico do $\mathrm{GA}_{3}$ na germinação de sementes de maracujazeiro-amarelo ( $P$. edulis) também relatado por SANTOS et al. (2013). Os autores verificaram que a germinação estimada de $64,0 \%$ foi obtida na concentração de $100,0 \mathrm{mg} \mathrm{L}^{-1}$ de $\mathrm{GA}_{3}$, obtendo-se um acréscimo de $42,0 \%$ em relação ao controle.

Tabela 2. Comprimento de plântulas (COMP), biomassa seca de plântulas (BMSP) percentagem de germinação (PG), índice de velocidade de germinação (IVG) e tempo médio de germinação (TMG) de sementes de granadilla, tratadas com ácido giberélico $\left(\mathrm{GA}_{3}\right)$.

Table 2. Seedling length (COMP), dry weight of seedling (BMSP), germination percentage (PG), emergence velocity index (IVG) and mean germination time (TMG) of sweet granadilla passion fruit seeds, treated with gibberellic acid $\left(G A_{3}\right)$.

\begin{tabular}{lccccc}
\hline Tratamentos & COMP & BMSP & PG & IVG & TMG \\
\cline { 2 - 6 } & $(\mathrm{cm})$ & $(\mathrm{mg} /$ plântula $)$ & $(\%)$ & & (dias) \\
\hline $0 \mathrm{mg} \mathrm{L}^{-1} \mathrm{GA}_{3}$ & $2,1 \mathrm{~b}^{*}$ & $2,67 \mathrm{~b}$ & $27,2 \mathrm{~b}$ & $0,4224 \mathrm{~b}$ & $15,59 \mathrm{a}$ \\
$100 \mathrm{mg} \mathrm{L}^{-1} \mathrm{GA}_{3}$ & $3,12 \mathrm{a}$ & $6,47 \mathrm{a}$ & $49 \mathrm{a}$ & $0,8687 \mathrm{a}$ & $14,31 \mathrm{~b}$ \\
\hline $\mathrm{CV}(\%)$ & 7,75 & 14,87 & 11,62 & 13,30 & 4,86 \\
\hline
\end{tabular}

*Médias seguidas de mesma letra minúscula na coluna não diferem estatisticamente entre si, pelo Teste de Tukey, a $5 \%$ de probabilidade de erro. 
Os resultados para a germinação de sementes de espécies frutíferas obtidos em laboratório podem ser utilizados para predizer o seu comportamento germinativo e o desenvolvimento das plântulas em condições naturais, em seu ambiente de cultivo. Nesse sentido, observa-se que temperaturas alternadas e utilização do ácido giberélico foram mais favoráveis a quebra de dormência e desempenho fisiológico das sementes, com respostas no desenvolvimento das plântulas de $P$. ligularis.

Devido à escassez de literatura com relação a germinação da espécie $P$. ligularis, trabalhos futuros devem ser realizados em relação ao seu armazenamento, temperaturas alternadas e concentrações de fitormônios para a quebra de sua dormência.

\section{CONCLUSÕES}

Melhores resultados foram obtidos para as sementes de granadilha foram verificados com a utilização de $100 \mathrm{mg} \mathrm{L}^{-1}$ de $\mathrm{GA}_{3}$ e em temperatura alternada de $20-30{ }^{\circ} \mathrm{C}$.

Maior percentagem de germinação de sementes de granadilha foi $53,2 \%$ na temperatura de $20-30{ }^{\circ} \mathrm{C}$ alternado.

\section{REFERÊNCIAS}

ALVES CZ et al. 2011. Adequação da metodologia para o teste de germinação de sementes de pitaia vermelha. Ciência Rural 41: 779-784.

AMARO HTR et al. 2014. Umedecimento do substrato e temperatura na germinação e vigor de sementes de melão. Semina: Ciências Agrárias 35: 1119-1130.

BRASIL. Ministério da Agricultura, Pecuária e Abastecimento. 2009. Regras para análises de sementes. Ministério da Agricultura, Pecuária e Abastecimento. Secretaria de Defesa Agropecuária. Brasília, DF: Mapa/ ACS. 399p.

CÁRDENAS $\mathrm{J}$ et al. 2013. Effect of $\mathrm{GA}_{3}, \mathrm{KNO}_{3}$, and removing of basal Point of seeds on germination of sweet granadilla (Passiflora ligularis Juss) and yellow Passion fruit (Passiflora edulis f. flavicarpa). Revista Brasileira de Fruticultura 35: 853-859.

CARVALHO NM de \& NAKAGAWA J. 2012. Sementes: ciência, tecnologia e produção. 4.ed. Jaboticabal: FUNEP. 588p.

CAVUSOGLU A \& SULUSOGLU M. 2015. The effects of exogenous gibberellin on seed germination of the fruit species. Türk Bilimsel Derlemeler Dergisi 8: 6-9.

FERRARI TB et al. 2008. Germinação de sementes de maracujá-doce (Passiflora alata Curtis): fases e efeito de reguladores vegetais. Biotemas 21: 65-74.

FERREIRA DF. 2011. Sisvar: a computer statistical analysis system. Ciência e Agrotecnologia 35: 1039-1042. LABOURIAU LG. 1983. A germinação das sementes. Washington: Secretaria-Geral da Organização dos Estados Americanos. 174p.

LIMA CSM et al. 2009. Germinação de sementes e crescimento de maracujá em diferentes concentrações do ácido giberélico, tempos de imersão e condições experimentais. Revista Brasileira de Agrociência 15: 4348.

MAGUIRE JD. 1962. Speed of germination aid in selection and evaluation for seedling emergence and vigor. Crop Science 2: 176-177.

MARCOS FILHO J. 2015. Fisiologia de sementes de plantas cultivadas. 2.ed. Londrina: ABRATES. 659p.

OLIVEIRA JR. et al. 2010. Superação de dormência de maracujá-do-mato (Passiflora cincinnata Mast.). Revista Brasileira de Fruticultura 32: 584-590.

PÁDUA JG et al. 2011. Germinação de sementes de Passiflora setacea e dormência induzida pelo armazenamento. Revista Brasileira de Sementes 33: 80-85. POSADA P et al. 2014. Estudio del comportamiento fisiológico de la semilla de tres especies cultivadas de Passiflora L. (Passifloraceae) como una contribución para la conservación ex situ. Revista Colombiana de Ciencias Hortícolas 8: 9-19.

REGO MM et al. 2014. Evaluation of different methods to overcome in vitro seed dormancy from yellow passion fruit. African Journal of Biotechnology 13: 3657-3665.

RODRÍGUEZ LF \& BERMÚDEZ LT. 2009. Economía y gestión del sistema de producción de passifloráceas em Colombia. En: MIRANDA D et al. (Eds.). Cultivo, poscosecha y comercialización de las passifloráceas em Colombia: maracuyá, granadilla, gulupa y curuba. Sociedad Colombiana de Ciencias Hortícolas: Bogotá. p.303-326.

SABIÃO RR et al. 2011. Enraizamento de estacas de Passiflora nitida submetidas a diferentes concentrações de ácido indolbutírico (AIB). Revista Brasileira de Fruticultura 33: 654-657.

SANTOS CAC et al. 2013. Germinação de sementes e vigor de plântulas de maracujazeiro amarelo submetidos à ação do ácido giberélico. Bioscience Journal 29: 400-407.

SANTOS CEM et al. 2015. Germination and emergence of passion fruit (Passiflora edulis) seeds obtained by self- and open-pollination. Acta Scientiarum. Agronomy 37: 489493.

SOUZA AD et al. 2015. Tempo e Condição de Armazenamento das Sementes na Germinação e Desenvolvimento de Passiflora ligularis Juss. Revista em Agronegócio e Meio Ambiente. 8: 181-192.

TAIZ L \& ZEIGER E. 2013. Fisiologia vegetal. 5.ed. Porto Alegre: Artmed. 954p.

WELTER MK et al. 2011. Germinação de sementes de maracujá amarelo azedo em função de tratamentos 
térmicos. Revista Agro@mbiente On-line 5: 227-232.

ZUCARELI V et al. 2009. Fotoperíodo, temperatura e reguladores vegetais na germinação de sementes de Passiflora cincinnata Mast. Revista Brasileira de Sementes 31: 106-114.

ZUCARELI $\mathrm{V}$ et al. 2015. Influence of light and temperature on the germination of Passiflora incarnata $\mathrm{L}$. seeds. Journal of Seed Science 37: 162-167. 